\title{
Early Predictors of Separation Anxiety Disorder: Early Stranger Anxiety, Parental Pathology and Prenatal Factors
}

\author{
Kristen Lavallee $^{\mathrm{a}}$ Chantal Herren $^{\mathrm{a}}$ Judith Blatter-Meunier ${ }^{\mathrm{a}}$ Carmen Adornetto $^{\mathrm{b}}$ \\ Tina In-Albon ${ }^{a}$ Silvia Schneider ${ }^{c}$

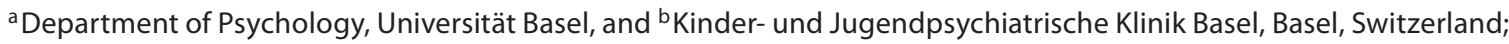 \\ 'Department of Psychology, Ruhr-Universität Bochum, Bochum, Germany
}

\section{Key Words}

Separation anxiety disorder - Parental pathology •

Prenatal risk factors $\cdot$ Pregnancy $\cdot$ Stranger anxiety

\begin{abstract}
Objective: The present study seeks to extend research on the etiology of separation anxiety disorder (SAD) in a German-speaking sample by examining differences between children with SAD and healthy comparisons, using a retrospective-reporting paradigm. Method: The sample included 106 children with SAD and 44 healthy children between the ages of 4 and 14 years. Parents completed questionnaires and structured clinical interviews to assess parental pathology, pregnancy variables and strong early stranger anxiety. Results: Children with SAD were more likely than healthy children to have had a phase of stronger stranger anxiety in infancy. Further, early stranger anxiety remained a significant predictor of SAD after controlling for maternal depression. Meaningful effects were not found for the influence of parental age at birth or other pregnancy factors. Conclusion: This study provides beginning evidence of the potential predictive value of strong stranger anxiety in distinguishing children with SAD from those with no disorder, above and beyond the influence of parental pathology.
\end{abstract}

Copyright $\odot 2011$ S. Karger AG, Basel
Separation anxiety disorder (SAD) is defined as anxiety over being away from a loved one, usually a parent, and is one of the most common anxiety disorders in children under 18 years of age [1], with median prevalence rates between 1.09 and 4.1\% in English-speaking children aged 5-11 [2-4] and 0.75\% in Swiss children aged $7-16$ years [5]. Further, SAD is a well-established predictor of later psychopathology, including depression, panic disorder with and without agoraphobia [6-8], generalized anxiety disorder, obsessive-compulsive disorder, bipolar disorder, pain disorder, alcohol dependence [9], specific phobia, posttraumatic stress disorder and acute stress [10]. Despite its significance, a thorough etiological profile of the factors contributing to SAD is not yet complete.

Current models of the development of anxiety in children tend to focus on anxiety disorders in general, and have not been specifically tested with children with specific disorders such as SAD. Further, existing models, while expansive, may not be completely comprehensive.

Portions of this study were presented at the 31st International School Psychology Association Conference, Bugibba, Malta, 2009, and at the 11th Congress of the Swiss Psychological Society, Neuchâtel, Switzerland, 2009.

\section{KARGER}

Fax +41613061234 E-Mail karger@karger.ch www.karger.com

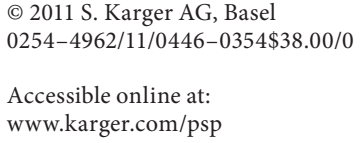

Kristen Lavallee, $\mathrm{PhD}$

Department of Psychology, Universität Basel

Missionsstrasse 60/62

$\mathrm{CH}-4055$ Basel (Switzerland)

Tel. +41 6126706 53,E-Mail Kristen.Lavallee@ unibas.ch 
For example, in their seminal model, Manassis and Bradley [11] propose a set of factors contributing to anxiety disorders that includes an interplay between innate temperament (encompassing genetic predispositions and behavioral inhibition) and insecure parent-child attachment stemming from the caregiver's nonautonomous state of mind and subsequent parenting style, and resulting in dysfunctional cognitions and diminished coping and social skills. Contributing to this process over time are cognitive maturation, developmental events and traumatic events. Tempering the effects of parenting style and attachment are relationships with others. In a separate model of generalized anxiety disorder, which can be generalized to other anxiety disorders as well, Rapee [12] outlines an unfolding of similar factors in the etiology of anxiety, presenting an even broader model than that of Manassis and Bradley. Rapee postulates that parental pathology, specifically parental anxiety, influences both the child's genetic tendencies (temperament in Manassis and Bradley) and parental reactions or style (attachment in Manassis and Bradley). Further, Rapee acknowledges the role of nonspecific stressors in addition to specific traumatic events in contributing to the development of anxiety. Although both models encompass a spectrum of both endogenous and exogenous factors, neither model specifically includes the contribution of the prenatal environment, although evidence indicates that it may indeed play a role in the development of anxiety [13].

Support for the link between parental pathology and SAD has been documented in studies indicating that parents with panic disorder $[14,15]$ and major depressive disorder both separately [15] and comorbidly [16], as well as parents with agoraphobia [17], are more likely to have offspring with SAD. Further, a longitudinal study with over 900 New Zealand children found that mothers' fear at the child age of 9 predicted child separation anxiety at the age of 11 [18]. Both the models of Rapee [12] and Manassis and Bradley [11] indicate that the link between parental pathology and child anxiety may flow through 2 pathways: via innate child temperament or via parental reactions. In the present study, unusually strong infant stranger anxiety may serve as a stand-in indicator of early child temperament (behavioral inhibition and avoidance). Stranger anxiety can also be conceived of as an age-dependent developmental task, a concept developed over half a century ago [19]. Unsuccessful mastery of such developmental tasks may contribute to the later development of maladaptive behavior and mental disorder [20]. While the link specifically between unusually strong stranger anxiety and SAD has not yet been examined, research does support the link from temperament to SAD. For example, longitudinal research has indicated that inhibition in infancy is related to SAD in children 3 years later [21].

Compared with research on the influence of parental pathology and infant temperament, no studies were found that examined the effects of prenatal factors on SAD specifically, despite first evidence that prenatal stress, for example, appears to increase general vulnerability to later psychopathology [22], including anxiety [13]. Maternal stress seems to influence the intrauterine milieu by producing a cascade of hormonal reactions and changes in blood flow to the uterus influencing the development of the hypothalamic-pituitary-adrenal axis in the fetus [23]. In one study, maternal stress during pregnancy accounted for $10 \%$ of the variance in infant fearfulness between 14 and 19 months [24]. Other pregnancy and birth factors have also been shown to impact later psychopathology, behavior problems, and cognition via their teratogenic effects on the developing nervous system. For example, it has been shown that maternal smoking during pregnancy tends to lead to child behavior difficulties [25, 26], alcohol consumption is associated with an increased risk for child anxiety [27], and low birth weight is associated with an increased risk of child depression [28] and difficulty making social contacts [29]. Finally, one study found that highly anxious children (as measured by a questionnaire tapping several types of anxiety symptoms, including those of panic, generalized anxiety, social phobia, separation anxiety, obsessivecompulsive disorder, posttraumatic stress and specific phobia) were exposed to more prenatal risk factors than moderately anxious children, as measured using a prenatal risk factor composite score, including physical illnesses, smoking, alcohol, maternal age over 34, low birth weight and premature birth, among other risk factors (standardized $\beta=0.22$ ) [30]. No studies were found regarding the effects of prenatal risk factors on SAD specifically and few were found on certain aspects of prenatal risk as they relate to child anxiety, such as maternal illness examined alone, rather than as part of a composite score. Further, the existing studies do not provide definitive, consistent results. For example, in contrast to Simon et al. [30], in an examination of maternal physical illness (i.e. infections, rubella, high blood pressure, diabetes, anemia, premature bleeding or contractions) during pregnancy as a stand-alone factor (composite illness and individual illnesses), Allen et al. [31] did not find an effect of illness on later anxiety in offspring. 


\section{The Present Study}

The current study aims to contribute to knowledge of the etiology of SAD by focusing on the role of prenatal factors in addition to intense early stranger anxiety and parental pathology (as derived from prior models) in the development of childhood SAD, and it is the first known study to examine prenatal risk and early stranger anxiety in relation to SAD. Children with SAD and children without mental disorders are expected to differ along these dimensions. Based on prior research, children with SAD were predicted to be more likely than healthy children to have mothers who smoked, drank alcohol and/or experienced high levels of stress while pregnant. They were also expected to have experienced higher levels of overall prenatal risk, including maternal age over 34 , maternal illnesses and low birth weight. After birth, they were expected to have displayed stronger stranger anxiety than children without SAD. Consistently with past findings in the area of parental pathology, children with SAD were expected to be more likely than healthy children to have parents with lifetime affective and panic diagnoses, and parents with higher current depression and anxiety ratings.

\section{Method}

\section{Study Design}

The present study was conducted at the Department of Clinical Child and Adolescent Psychology at the University of Basel, Switzerland, from December 2004 to January 2009, and was reviewed and approved by the local ethics committee for medical research. Children participated as part of a broader study on the treatment and etiology of SAD. All assessments in the present study took place before treatment began.

\section{Participants}

Participants were recruited by local child and adolescent psychiatrists, psychological therapists, pediatricians, psychological services and psychiatric clinics, which received information about the study, its goals, and the free assessment and treatment for children with SAD. Participants were also recruited by newspaper advertisements and flyers. Children went through an initial screening and then were assessed for the presence of SAD and other disorders using criteria outlined in the Diagnostic and Statistical Manual for Mental Disorders - Text Revision (DSM-IVTR) [32]. Inclusion criteria for the present study were knowledge of the German language, age between 4 and 14 years, and written parental informed consent and verbal child assent to randomized assignment to either the immediate treatment condition or the waiting list condition for the children with SAD, as well as to completion of psychological assessments for both children with and without SAD. Children were excluded if they had a comorbid pervasive developmental disorder, major developmental or cognitive delay, or if they were taking psychotropic medication. Par- ticipating families received free diagnostic assessment, monetary compensation (families of non-SAD children) and treatment (for families of children with SAD) for their participation in the study.

Four hundred forty-seven families contacted the department and underwent a telephone screening for participation in studies involving children with separation anxiety, children with other anxiety disorders and children with no disorder. One hundred seventy-two children and their parents were included in the present study as part of either the healthy (diagnosis-free) or SAD sample. Two-hundred and seventy-five children did not participate in the present study either because they were not interested after the telephone screening, or were excluded due to age, language or not meeting target diagnostic criteria. Some children who called were included in other studies as children with other anxiety disorders. The present sample included 44 healthy children with no psychological disorders ( 22 girls, 22 boys; mean age 9.83 years, SD 2.27) and 106 children with SAD (57 girls, 49 boys; mean age 8.80 years, SD 2.37). The children without SAD were older than the children with SAD, with $\mathrm{t}(148)=2.44$ and $\mathrm{p}<0.05$. The mean family income was 3.79 (SD 1.55) for control children and 3.68 (SD 1.52) for children with $\mathrm{SAD}$, on a scale ranging from $1(<2,000 \mathrm{CHF} / \mathrm{month})$ to $6(>10,000 \mathrm{CHF} / \mathrm{month})$, with $3=$ $4,000-6,000 \mathrm{CHF} / \mathrm{month}$ and $4=6,000-8,000 \mathrm{CHF} / \mathrm{month}$. The two groups did not significantly differ in household income $[\mathrm{t}(140)=0.38, \mathrm{p}>0.05]$. Comorbid diagnoses were present in 54 children in the SAD group. The following disorders were present, with multiple comorbidity in some children: additional anxiety disorders (49), sleeping disorders (13), behavior disorders (6; oppositional defiant disorder, attention deficit/hyperactivity disorder), tic disorders (4), affective disorders (2) and elimination disorders (2).

\section{Measures}

Clinical Diagnoses. The Diagnostic Interview for Children and Youth for DSM-IV-TR: Parent Version (Kinder-DIPS; DSM-IVTR German version) [33] is a structured interview designed to assess mental disorders in children according to criteria as outlined in the DSM-IV-TR [32]. Qualified clinical psychologists or graduate students who underwent standardized Kinder-DIPS training provided diagnoses following separate parent and child interviews. Clinician-based diagnoses were based on information combined from parent and child interviews for children 8 years of age or older, counting a disorder as present when criteria were met based on either parent or child report. Diagnoses were based on parent interview only for children younger than 8 . The KinderDIPS has good validity and retest reliability for all axis I primary diagnoses (child version: $\kappa=0.48-0.88$; parent version: $\kappa=0.74-$ $0.96)$, as well as good interrater reliability for anxiety diagnoses $(\kappa=0.85$, Yule's $Y=0.99)$ and other axis I disorders $(\kappa=0.85-0.94)$ [33]. Parent-child agreement for SAD is moderate ( $\kappa=0.54$, Yule's $\mathrm{Y}=0.94$ ) [33]. Interrater reliability estimates for the current sample calculated on a random subset of cases (between 29 and 40\%) were good for both SAD ( $\kappa=0.92$ for parents and 0.85 for children) and social phobia ( $\kappa=0.79$ for parents and 0.90 for children). Diagnoses were used to determine child diagnostic status and to classify children into the groups of interest including healthy children and children with SAD.

Pregnancy Risk. Mothers completed a questionnaire soliciting information about the pregnancy, and were asked to indicate the presence of, amount and/or type of the following during preg- 
nancy: maternal physical illness, tobacco use and alcohol consumption. Mothers were asked on 2 additional items to indicate whether the child was born prematurely (before 37 weeks) and to provide the birth weight of the child (in grams, the commonly used metric for the current population). Maternal age at childbirth (calculated from the mother and child birth dates), premature birth (coded as 0 or 1 for birth at or before 37 weeks), maternal physical illness (presence coded as 0 for none or 1 for present), smoke exposure (presence coded as 0 or 1 for daily smoking of 1 or more cigarettes, and/or regular in-house second-hand smoking of 5 or more cigarettes/day), alcohol consumption (presence coded as 0 for none or 1 for present) were examined separately. The first author worked with a medical doctor in the obstetrics department of the local university women's hospital to determine the cutoffs for these factors, as well as to calculate a summary total number of prenatal risk factors experienced by each mother. As in prior research on prenatal risk and anxiety [30], those factors thought to have the capacity for affecting brain development were included in the count. Medical factors that increase the risk for prematurity were also included. Prenatal risk factors included regular maternal smoking (daily smoking of 1 or more cigarettes), regular in-house second-hand smoking of 5 or more cigarettes/ day, regular alcohol consumption, maternal age 35 or older, prematurity (born at the 37th week or earlier), dysmaturity (weight under 2,500 g) and other medical conditions (severe illness/ vomiting, maternal vaginal bleeding, irregular heart beat, prior stillbirth, high blood pressure, hypertonia, toxoplasmosis, preeclampsia, cystitis, arrhythmia, preterm contractions, membrane rupture, failure to thrive, twins and fibroid tissue). The number of prenatal risk factors was summed for an overall prenatal risk score.

Pregnancy Stress. Mothers were asked to indicate whether they experienced stress during pregnancy using a 32-item checklist assessing major life changes and stressors across 4 domains: social (family, friends, partner, death, major changes such as a marriage or divorce, etc.), work-related (change/lost job, unhappy with job, fights with the boss or colleagues, etc.), financial (poverty, financial distress, etc.) and legal (arrests, lawsuits, victim of a crime, etc.). Mothers were also allowed to write in additional stressors in each domain. The presence of additional stressors in each domain ( 0 or 1 ) was added to the total count. The number of stressors was added for each mother, and this sum was used as an overall indicator of pregnancy stress.

Early Strong Stranger Anxiety. Mothers were asked to indicate on one dichotomous item (yes/no) whether their child had stranger anxiety as an infant. As some stranger anxiety during infancy is developmentally typical, and almost all mothers reported some stranger anxiety, mothers were asked to additionally indicate whether there was a period of stronger stranger anxiety in infancy (6-24 months) by checking a box (i.e. dichotomous, yes/no item). The presence of a period of strong stranger anxiety was used in the analyses as a dichotomous indicator of strong stranger anxiety.

Parental Pathology. Parental pathology was assessed using 2 questionnaires and structured diagnostic interviews for both mothers and fathers. Parents completed the German version of the Beck Anxiety Inventory [34] (German version [35]) to assess manifestations of general anxiety. It is a well-established 21-item self-report measure, with items assessing the severity of anxiety symptoms such as 'nervous' and 'light-headed' during the past 7 days on a scale ranging from 0 (not at all) to 3 (strong). Scores are calculated by summing the responses for each item, for a final score ranging from 0 to 63 . Cronbach's alpha for the German version in the current sample was 0.89 for mothers and 0.88 for fathers.

Mothers and fathers also individually completed the Beck Depression Inventory [36] (German version [37]) to assess manifestations of general depression. It is a well-established 21-item selfreport measure, with items assessing the severity of depression symptoms such as sadness during the past 7 days on a scale which presents statements of increasing strength regarding the symptoms ranging from 0 (not at all) to 3 (strong). Scores are calculated by summing the responses for each item, for a final score ranging from 0 to 63 . Cronbach's alpha for the German version in the current sample was 0.86 for mothers and 0.81 for fathers.

The Structured Diagnostic Interview for Mental Disorders (DIPS for DSM-IV-TR) [38] is a German language structured interview designed to assess mental disorders in adults according to DSM-IV-TR [32] criteria. Parent reports of their own symptoms and impairment during an interview with a trained clinician are used to determine present and lifetime diagnoses across a wide range of disorders, including anxiety disorders and depression. The DIPS has demonstrated good validity for anxiety diagnoses, affective disorders, somatoform disorders, eating disorders, substance disorders and for the status of no diagnosis, with less wellestablished validity for sleeping disorders [39]. Interrater reliability is good for anxiety diagnoses, affective disorders, eating disorders, substance disorders, sleeping disorders and for the status of no diagnosis, with $\kappa$ between 0.72 and 0.92 . Test-retest reliability is also good for anxiety diagnoses, affective disorders, somatoform disorders, eating disorders and substance disorders, with $\kappa$ between 0.62 and 0.94 , and is lower for sleeping disorders, with $\kappa=$ 0.35 [40]. For the present study, mothers and fathers were assigned a 1 if they had a lifetime diagnosis of any emotional disorder, including generalized anxiety, panic, phobias, major depression, dysthymia or bipolar disorder, and a 0 for no lifetime affective disorder. They were also separately assigned a 1 if they had a lifetime diagnosis of panic disorder (with or without agoraphobia), and a 0 for no lifetime panic disorder. The presence of lifetime (current or past) affective disorders and lifetime panic disorder was examined separately in mothers $(n=127)$ and fathers $(n=96)$. Other disorders were not examined in the present study.

\section{Statistical Analyses}

To test for differences between groups, $t$ tests were conducted on all continuous variables, and the $\chi^{2}$ test on all dichotomous variables. A hierarchical logistic regression was conducted to follow up on significant main between-group effects.

\section{Results}

Post hoc power analysis was conducted using $\mathrm{G}^{*}$ Power 3 [41], using the significance level of 0.05 with the full sample size of 150 . Results indicated power ( $1-\beta$ error probability) of 0.96 for a small effect size (0.30) using the $\chi^{2}$ test for the dichotomous variables (or power of 0.80 if assuming both groups had only as many participants as 
Table 1. $t$ and $\chi^{2}$ tests for parental affective ratings and diagnoses

\begin{tabular}{|c|c|c|c|}
\hline Group & $\mathrm{n}$ & Mean $\pm \mathrm{SD}$ & $\mathrm{t}$ \\
\hline \multicolumn{4}{|c|}{ Current maternal anxiety } \\
\hline Control & 41 & $0.25 \pm 0.32$ & \multirow[t]{2}{*}{$-1.78(140)$ trend } \\
\hline SAD & 101 & $0.37 \pm 0.37$ & \\
\hline \multicolumn{4}{|c|}{ Current maternal depression } \\
\hline Control & 41 & $0.18 \pm 0.17$ & \multirow[t]{2}{*}{$-3.21(140)^{* *}$} \\
\hline SAD & 101 & $0.32 \pm 0.26$ & \\
\hline \multicolumn{4}{|c|}{ Current paternal anxiety } \\
\hline Control & 30 & $0.18 \pm 0.24$ & \multirow{2}{*}{$-1.02(115)$} \\
\hline SAD & 87 & $0.24 \pm 0.26$ & \\
\hline \multicolumn{4}{|c|}{ Current paternal depression } \\
\hline Control & 30 & $0.15 \pm 0.18$ & \multirow[t]{2}{*}{$-1.61(115)$} \\
\hline SAD & 87 & $0.22 \pm 0.20$ & \\
\hline Group & $\mathrm{n}$ & $\%$ & $\chi^{2}$ \\
\hline \multicolumn{4}{|c|}{ Lifetime maternal affective diagnosis } \\
\hline Control & 43 & 25.60 & \multirow[t]{2}{*}{3.64 (1) trend } \\
\hline SAD & 84 & 42.90 & \\
\hline \multicolumn{4}{|c|}{ Lifetime paternal affective diagnosis } \\
\hline Control & 20 & 5.00 & \multirow[t]{2}{*}{2.80 (1) trend } \\
\hline SAD & 76 & 21.10 & \\
\hline
\end{tabular}

Figures in parentheses indicate degrees of freedom; trend $=$ $\mathrm{p}<0.10 ;{ }^{* *} \mathrm{p}<0.01$.

the control group) and 0.97 for a medium effect size (0.50) using $\mathrm{t}$ tests for the continuous variables. Acceptable power is often considered 0.80 [42], and thus the present study had sufficient power to test small effects on the dichotomous variables, and medium effects on the continuous variables.

Means and standard deviations by group are presented in tables 1 (parental pathology) and 2 (pregnancy and stranger anxiety). Between-group tests indicated 1 significant effect of parental pathology. That is, mothers of children with SAD reported more current depression than children without SAD (effect size $d=0.54$ ). Current maternal anxiety and lifetime maternal and paternal affective disorders only approached significance at the trend level. The two groups did not differ on current paternal affective ratings.

Results did not indicate any significant effects of stress during pregnancy, nor did they indicate significance for prenatal risk factors, either combined or separately. Finally, results indicated that children with SAD were somewhat more likely to have had a period of stronger stranger anxiety than children without SAD (effect size
Table 2. $t$ and $\chi^{2}$ tests for pregnancy variables and strong infant stranger anxiety

\begin{tabular}{|c|c|c|c|}
\hline Group & $\mathrm{n}$ & Mean \pm SD & $\mathrm{t}$ \\
\hline \multicolumn{4}{|c|}{ Pregnancy stress } \\
\hline Control & 43 & $1.07 \pm 1.06$ & \multirow[t]{2}{*}{$-0.01(139)$} \\
\hline SAD & 98 & $1.07 \pm 1.15$ & \\
\hline \multicolumn{4}{|c|}{ Prenatal risk factors sum } \\
\hline Control & 39 & $0.82 \pm 0.88$ & \multirow[t]{2}{*}{$-0.60(125)$} \\
\hline SAD & 88 & $0.93 \pm 1.00$ & \\
\hline \multicolumn{4}{|l|}{ Maternal age } \\
\hline Control & 44 & $31.26 \pm 4.58$ & \multirow[t]{2}{*}{$-0.28(146)$} \\
\hline SAD & 104 & $31.48 \pm 4.33$ & \\
\hline \multicolumn{4}{|l|}{ Paternal age } \\
\hline Control & 40 & $33.94 \pm 6.02$ & \multirow[t]{2}{*}{$-0.53(137)$} \\
\hline SAD & 99 & $34.49 \pm 5.39$ & \\
\hline Group & $\mathrm{n}$ & $\%$ & $\chi^{2}$ \\
\hline \multicolumn{4}{|l|}{ Premature } \\
\hline Control & 42 & 11.90 & \multirow[t]{2}{*}{$0.10(1)$} \\
\hline SAD & 99 & 10.10 & \\
\hline \multicolumn{4}{|c|}{ Maternal physical illness } \\
\hline Control & 42 & 19.00 & \multirow[t]{2}{*}{$0.07(1)$} \\
\hline SAD & 99 & 17.20 & \\
\hline \multicolumn{4}{|c|}{ Smoke exposure } \\
\hline Control & 43 & 16.30 & \multirow[t]{2}{*}{$1.00(1)$} \\
\hline SAD & 101 & 23.80 & \\
\hline \multicolumn{4}{|c|}{ Alcohol consumption } \\
\hline Control & 42 & 31.00 & \multirow[t]{2}{*}{$1.28(1)$} \\
\hline SAD & 100 & 22.00 & \\
\hline \multicolumn{4}{|c|}{ Strong stranger anxiety } \\
\hline Control & 39 & 10.30 & \multirow[t]{2}{*}{$9.70(1)^{* *}$} \\
\hline SAD & 91 & 37.2 & \\
\hline
\end{tabular}

Figures in parentheses indicate degrees of freedom; ${ }^{* *} \mathrm{p}<0.01$.

Somers' $d=0.27$ ). To follow up this effect, a hierarchical logistic regression was conducted with diagnosis as the outcome variable, maternal pathology (current depression and anxiety ratings as well as lifetime diagnosis) on the first step, and strong stranger anxiety on the second step. Paternal pathology was not included as data were incomplete for fathers, and this significantly reduced the sample size. Although the two groups (SAD/control) differed on child age, child age was not correlated with any predictors in the model and thus was not included in the model. Gender was not significantly related to any predictors in the model either, and was thus not included. The model including only maternal current and lifetime pathology indicated that current maternal depression 
Table 3. Logistic regression results

\begin{tabular}{lcc}
\hline & B & Odds ratio \\
\hline Step 1, step $\chi^{2} \Delta(3)=11.75^{* *}$ & & \\
Constant & $-0.20(0.54)$ & 0.82 \\
Current maternal depression & $3.78(1.45)^{* * *}$ & $43.94[2.56-753.77]$ \\
Current maternal anxiety & $0.28(0.71)$ & $1.33[0.33-5.31]$ \\
Lifetime maternal affective & $-1.18(0.47)$ & $0.84[0.33-2.10]$ \\
\hline Step 2, step $\chi^{2} \Delta(1)=9.21^{* *}$ & & \\
Constant & $1.15(0.76)$ & 3.16 \\
Current maternal depression & $3.85(1.49)^{*}$ & $47.20[2.55-874.82]$ \\
Current maternal anxiety & $0.09(0.73)$ & $1.10[0.26-4.55]$ \\
Lifetime maternal affective & $-0.23(0.49)$ & $0.78[0.31-2.07]$ \\
Strong infant stranger anxiety & $-1.64(0.60)^{* *}$ & $0.19[0.06-0.63]$ \\
\hline
\end{tabular}

$\mathrm{n}=110 ;{ }^{*} \mathrm{p}<0.05 ;{ }^{* *} \mathrm{p}<0.01$; step $1 \mathrm{R}^{2}=0.10$ (Cox and Snell), 0.14 (Nagelkerke); step $2 \mathrm{R}^{2}=0.17$ (Cox and Snell), 0.24 (Nagelkerke).

Figures in parentheses indicate standard errors, those in square brackets $95 \%$ confidence intervals.

was a significant predictor of SAD diagnosis (odds ratio $=43.94)$. The model including strong stranger anxiety on the second step provided a significant improvement to the model over step 1 [step $\chi^{2} \Delta(1)=9.21, \mathrm{p}<0.01$ ], with both current maternal depression and strong stranger anxiety (odds ratio $=0.19$ ) as significant predictors.

\section{Discussion}

The present study explored the potential value of prenatal factors and infant stranger anxiety in understanding the etiology of SAD above and beyond parental pathology. Results indicated that children with SAD were more likely than healthy children to have had a phase of stronger stranger anxiety in infancy and to have mothers with higher current depression ratings. Further, stranger anxiety was a significant predictor of SAD diagnosis even after controlling for current maternal pathology. Meaningful effects were not found for the influence of parental age at birth or other pregnancy factors.

This is, to our knowledge, the first study indicating that strong stranger anxiety is a predictor of later SAD, suggesting that a period of stronger stranger anxiety in infancy may be an early indicator of later separation anxiety and may be an important sign to watch for, especially in children with a family history of anxiety disorders. As stranger anxiety is the earliest anxiety a child experiences in life [43], strong stranger anxiety may be thought of as serving as a stand-in for temperament. In addition, understanding stranger anxiety as an age-dependent developmental task may give a new insight into our understanding of the etiology of SAD. It is conceivable that the occurrence of 'developmentally typical' stranger anxiety may serve as a first critical point of a biopsychosocial interface in the development of anxiety disorder. The successful versus unsuccessful mastery of this developmental task may set the child on a lower or higher risk for anxiety disorders in childhood. For a better understanding of this early risk period, further attention should certainly be given not only to infant temperament but also to the role of parental factors (e.g. parenting, parental cognition) and the concept of 'goodness of fit' between child temperament and parental style [44].

We did not find significantly increased lifetime affective or anxiety diagnoses in parents of children with SAD as compared to parents of healthy children. However, consistently with previous research, we did find that children with SAD had mothers with higher current depression ratings than mothers of children with no disorder. Due to the cross-sectional approach of the present study, it remains unclear whether maternal depression is related to increases in child SAD, or whether mothers with children with SAD are more likely to experience current levels of depression due to the stresses of having a child with SAD. The size of the effect was moderate, and it is possible that with increased power, more hypothesized, yet smaller effects with regard to current parent anxiety would have come to light. Power was sufficient to detect small effects with regard to lifetime affective diagnoses, yet these remained at the trend level.

Contrary to predictions, prenatal factors did not distinguish children with and without SAD in the present analyses. Despite adequate power to detect medium effect sizes for prenatal stress, parental age and the composite prenatal risk factors score, as well as to detect small effects on several individual prenatal variables (smoking, illness, alcohol use and preterm birth), no significant effects were detected. This is in contrast to the study of Simon et al. [30] of pregnancy factors and general anxiety, and may be either an indicator that these prenatal factors do not have a significant effect on the development of separation anxiety, or that the effects are quite small and require a larger sample size to detect. Indeed, the picture from the existing research is not definitive. While some studies point to prenatal teratogenic effects on internalizing symptoms (i.e. alcohol [27], low birth weight [28] and a composite of prenatal risk factors [30]), others have not found strong effects for these factors, indicating that 
child anxiety is primarily associated with maternal mental health during pregnancy and with postbirth child illness, but not necessarily with prenatal substance exposure or maternal illness [31]. Indeed, the effects of smoking, for example, may be stronger in the domain of externalizing, rather than internalizing disorders [45]. It could also be that the retrospective reports lacked the accuracy that would be present in a prospective study, although the data in Simon et al. [30] were also retrospective. In either case, the present findings should be replicated with a larger, and preferably community sample, as well as with a prospective sample, before they can be considered confirmed.

Finally, the limitations of the present study must be acknowledged. The present sample was largely clinically referred or self-referred, and was not representative of the population. Therefore, it was not possible to draw conclusions about the effects of early environment on SAD in the community at large. Furthermore, information on pregnancy and stranger anxiety was based on retrospective reports. For example, pregnancy stress was measured via a count of retrospectively reported major life changes and stressors. It could be that this method of assessment did not fully capture true pregnancy stress. Future research in this area would benefit from real-time ratings of pregnancy stressors or cortisol levels during pregnancy, as well as early stranger anxiety during infancy. In addition, in the present study, stranger anxiety was assessed using a single, dichotomous item. Improved rating scales, observational methods and multirater information (i.e. from fathers and clinicians) would improve the measurement accuracy of stranger anxiety and early development variables in future research. Replication of the present study should be undertaken in a representative sample using a prospective, multimethod, multirater, longitudinal approach and comparing children with SAD to children with other anxiety disorders.

In conclusion, the results of this study provide beginning evidence of the potential predictive value of strong stranger anxiety in distinguishing children with SAD from those with no disorder, above and beyond the influence of parental pathology. A next step should include a test of whether strong stranger anxiety is a specific risk factor for SAD, or a risk factor for child anxiety disorders in general in a study comparing children with SAD to children with other anxiety disorders. Further, future research should work toward a more specific and well-defined operational definition of abnormally strong stranger anxiety as a risk factor, and should utilize strengthened multi-item, multimethod measures as well as prospective reports from multiple informants. Finally, as research regarding prenatal risk factors is mixed, future research should further explore and examine the impact of the prenatal environment on the development of anxiety disorders in general, and SAD in particular.

\section{Key Points}

- Mothers of children with separation anxiety disorder (SAD) reported more current depression than mothers of healthy children.

- Lifetime parent affective diagnoses predicted SAD status only at the trend level.

- Strong infant stranger anxiety predicted SAD diagnostic status above maternal affective pathology.

- Paternal affective ratings did not emerge as a significant factor in discriminating children with SAD from healthy children.

- Prenatal risk factors, such as stress, smoking, alcohol use, illness, preterm birth, parental age and overall prenatal risk were nonsignificant in distinguishing children with SAD from those without.

\section{Acknowledgements}

This study was supported by grant PP001-68701, 105314116517, 'Etiology and Psychological Treatment of Separation Anxiety Disorder in Childhood', awarded to Prof. Silvia Schneider by the Swiss National Science Foundation. We appreciate the participants in this study, Andrea Meyer for his statistical assistance, and the research assistants and graduate students on the project at Universität Basel for their assistance in data collection and management.

References

-1 Last CG, Perrin S, Hersen M, Kazdin AE: DSM-III-R anxiety disorders in children: sociodemographic and clinical characteristics. J Am Acad Child Adolesc Psychiatry 1992; 31:1070-1076.

$\checkmark 2$ Cartwright-Hatton S, McNicol K, Doubleday E: Anxiety in a neglected population: prevalence of anxiety disorders in pre-adolescent children. Clin Psychol Rev 2006;26: 817-833.

3 Costello EJ, Mustillo S, Erkanli A, Keeler G, Angold A: Prevalence and development of psychiatric disorders in childhood and adolescence. Arch Gen Psychiatry 2003;60:837844

Lavallee/Herren/Blatter-Meunier/ Adornetto/In-Albon/Schneider 
4 Ford T, Goodman R, Meltzer H: The British Child and Adolescent Mental Health Survey 1999: the prevalence of DSM-IV disorders. J Am Acad Child Adolesc Psychiatry 2003;42: 1203-1211.

$\checkmark 5$ Steinhausen HC, Winkler Metzke C, Meier M, Kannenberg R: Prevalence of child and adolescent psychiatric disorders: the Zürich epidemiological study. Acta Psychiatr Scand 1998;98:262-271.

6 Lewinsohn PM, Holm-Denoma JM, Small JW, et al: Separation anxiety disorder in childhood as a risk factor for future mental illness. J Am Acad Child Adolesc Psychiatry 2008;47:549-556.

$\checkmark 7$ Manicavasagar V, Silove, D, Hadzi-Pavlovic D: Subpopulations of early separation anxiety: relevance to risk of adult anxiety disorders. J Affect Disord 1998;48:181-190.

$\checkmark 8$ Zitrin C, Ross DC: Early separation anxiety and adult agoraphobia. J Nerv Mental Dis 1988; 176:621-625.

-9 Brückl TM, Wittchen H-U, Höfler M, et al: Childhood separation anxiety and the risk for subsequent psychopathology: results from a community study. Psychother Psychosom 2007;76:47-56.

10 Aschenbrand SG, Kendall PC, Webb A, Safford SM, Flannery Schroeder E: Is childhood separation anxiety disorder a predictor of adult panic disorder and agoraphobia? a seven-year longitudinal study. J Am Acad Child Adolesc Psychiatry 2003;42:1478-1485.

11 Manassis K, Bradley SJ: The development of childhood anxiety disorders: toward an integrate model. J Appl Dev Psychol 1994;15: 345-366.

12 Rapee RM: The development of generalized anxiety; in Vasey MW, Dodds MR (eds): The Developmental Psychopathology of Anxiety. New York, Oxford University Press, 2001.

-13 Talge NM, Neal C, Glover V, Early Stress Translational Research and Prevention Science Network: Fetal and neonatal experience on child and adolescent mental health. Antenatal maternal stress and long-term effects on child neurodevelopment: How and why? J Child Psychol Psychiatry 2007;48:245-261.

-14 Unnewehr S, Schneider S, Margraf J, Florin I: Psychopathology in children of patients with panic disorder or animal phobia. Psychopathology 1998;31:69-84.

15 Warner V, Mufson L, Weissman MM: Offspring at high and low risk for depression and anxiety: mechanisms of psychiatric disorder. J Am Acad Child Adolesc Psychiatry 1995;34:786-797.

-16 Biederman J, Faraone SV, Hirshfeld-Becker DR, Friedman D, Robin JA, Rosenbaum JF: Patterns of psychopathology and dysfunction in high-risk children of parents with panic disorder and major depression. Am J Psychiatry 2001;158:49-57.
17 Capps L, Sigman M, Sena R, Henker B, Whalen C: Fear, anxiety and perceived control in children of agoraphobic parents. J Child Psychol Psychiatry 1996;37:445-452.

18 Poulton R, Milne BJ, Craske MG, Menzies RG: A longitudinal study of the etiology of separation anxiety. Behav Res Ther 2001;39: 1395-1410.

19 Havighurst RJ: Developmental Task and Education. New York, McKay, 1948.

20 Sroufe LA, Rutter M: The domain of developmental psychopathology. Child Dev 1984; 55:17-29.

-21 Biederman J, Rosenbaum JF, Bolduc-Murphy EA, Faraone SV, Chaloff J, Hirshfeld DR, et al: A 3-year follow-up of children with and without behavioral inhibition. J Am Acad Child Adolesc Psychiatry 1993;32:814-821.

22 Huizink AC, Mulder EJH, Buitelaar JK: Prenatal stress and risk for psychopathology: special effects or induction of general susceptibility? Psychol Bull 2004;130:115-142.

23 O'Connor TG, Heron J, Glover V, Alspac Study Team: Antenatal anxiety predicts child behavioral/emotional problems independently of postnatal depression. J Am Acad Child Adolesc Psychiatry 2002;412: 1470-1477.

24 Bergman K, Sarkar P, O’Connor TG, Modi N, Glover V: Maternal stress during pregnancy predicts cognitive ability and fearfulness in infancy. J Am Acad Child Adolesc Psychiatry 2007;46:1454-1463.

25 Herrmann M, King K, Weitzman M: Prenatal tobacco smoke and postnatal secondhand smoke exposure and child neurodevelopment. Curr Opin Pediatr 2008;20:184-190.

26 Weissman MM, Warner V, Wickramaratne PJ, Kandel DB: Maternal smoking during pregnancy and psychopathology in offspring followed to adulthood. J Am Acad Child Adolesc Psychiatry 1999;38:892-899.

27 Hellemans KGC, Sliwowska JH, Verma P, Weinberg J: Prenatal alcohol exposure: fetal programming and later life vulnerability to stress, depression and anxiety disorders. Neurosci Biobehav Rev 2010;34:791-807.

- 28 Frost AK, Reinherz HZ, Pakiz-Camras B, Giaconia RM, Lefkowitz ES: Risk factors for depressive symptoms in late adolescence: a longitudinal community study. Am J Orthopsychiatry 1999;69:370-381.

29 Hille ETM, Dorrepaal C, Perenboom R, Gravenhorst JB, Brand R, Verloove-Vanhorick SP: Social lifestyle, risk-taking behavior, and psychopathology in young adults born very preterm or with a very low birth weight. J Pediatr 2008;152:793-800.

30 Simon E, Bögels S, Stoel R, De Schutter S: Risk factors occurring during pregnancy and birth in relation to brain functioning and child's anxiety. J Anxiety Disord 2009;8: 1024-1030.
31 Allen NB, Lewinsohn PM, Seeley JR: Prenatal and perinatal influences on risk for psychopathology in childhood and adolescence. Dev Psychopathol 1998;10:513-529.

32 American Psychiatric Association: Diagnostic and Statistical Manual of Mental Disorders, Text Revision, ed 4. Washington, American Psychiatric Association, 2000.

33 Schneider S, Unnewehr S, Margraf J: Diagnostisches Interview bei psychischen Störungen im Kindes- und Jugendalter (Kinder-DIPS), ed 2. Heidelberg, Springer, 2009.

34 Beck AT, Epstein N, Brown G, Steer RA: An inventory for measuring clinical anxiety: psychometric properties. J Consult Clin Psychol 1988;56:891-893.

35 Margraf J, Ehlers A: Beck-Angst-Inventar (BAI). Testhandbuch. Göttingen, Hogrefe, 2002.

36 Beck A, Steer R, Brown G: Manual for Beck Depression Inventory-II. San Antonio, Psychological Corporation, 1996.

37 Hautzinger M, Bailer M, Worall H, Keller F: Beck-Depressions-Inventar (BDI). Testhandbuch, ed 3. Bern, Huber, 2000.

38 Schneider S, Margraf J: Diagnostisches Interview bei psychischen Störungen (DIPS für DSM-IV-TR), ed 3, rev. Berlin, Springer, 2006.

39 In-Albon T, Suppiger A, Schlup B, Wendler S, Margraf J, Schneider S: Validität des Diagnostischen Interviews bei psychischen Störungen (DIPS für DSM-IV-TR). Z Klin Psychol Psychother 2008;37:33-42.

40 Suppiger A, In-Albon T, Herren C, Bader K, Schneider S, Margraf J: Reliabilität des Diagnostischen Interviews bei Psychischen Störungen (DIPS für DSM-IV-TR) unter klinischen Routinebedingungen. Verhaltenstherapie 2008;18:237-244.

-41 Faul F, Erdfelder E, Lang AG, et al: G*Power 3: a flexible statistical power analysis program for the social, behavioral, and biomedical sciences. Behav Res Methods 2007;39: 175-191.

42 Cohen J: Statistical Power Analysis for the Behavioral Sciences. Hillsdale, Erlbaum Associates, 1988.

43 Sroufe LA: Emotional Development: The Organization of Emotional Life in the Early Years. Cambridge, Cambridge University Press, 1997.

44 Chess S, Thomas A: Goodness of Fit: Clinical Applications, from Infancy through Adult Life. Philadelphia, Brunner/Mazel, 1999.

45 Brennan P: Tobacco consumption during pregnancy and its impact on psychosocial child development; in Tremblay RE, Barr RG, Peters RDeV (eds): Encyclopedia on Early Childhood Development. Montreal, Centre of Excellence for Early Childhood Development, 2005, pp 1-5. 